Article

\title{
Impact of Credit Risk on Momentum and Contrarian Strategies: Evidence from South Asian Markets
}

\author{
Ahmed Imran Hunjra ${ }^{1}$, Tahar Tayachi ${ }^{2, *}$,, Rashid Mehmood $^{1}$, Sidra Malik $^{1}$ and Zoya Malik ${ }^{1}$ \\ 1 University Institute of Management Sciences, PMAS-Arid Agriculture University Rawalpindi, \\ Rawalpindi 46000, Pakistan; ahmedhunjra@gmail.com (A.I.H.); rashidm1005@gmail.com (R.M.); \\ sidramalik14@yahoo.com (S.M.); zoyamalik1237@gmail.com (Z.M.) \\ 2 Finance Department, Effat University, Jeddah 22332, Saudi Arabia \\ * Correspondence: ttayachi@effatuniversity.edu.sa
}

Received: 1 March 2020; Accepted: 9 April 2020; Published: 14 April 2020

\begin{abstract}
We examine the profitability of the momentum and contrarian strategies in three South Asian markets, i.e., Bangladesh, India, and Pakistan. We also analyze, whether credit risk influences momentum and contrarian return for these markets from 2008 to 2014. We use default risk that relates to non-payments of debts by firms as a measure of credit risk. For that purpose, we use distance to default (DD) by Kealhofer, McQuown, and Vasicek (KMV) model as a proxy of credit risk. We calculate the credit risk and form the momentum and contrarian strategies of the firms based on high, medium, and low risk. We find that in all three markets, the momentum and contrarian returns are significant for medium and high credit risk portfolios and no momentum and contrarian returns for low credit risk portfolios.
\end{abstract}

Keywords: momentum returns; contrarian returns; credit risk; stock market; KMV model

\section{Introduction}

The most popular phrase among the investing community is buying low and selling high. Every investor needs to decide the level of risk diversification for their stocks and industries portfolio investment to minimize risks considering expected return (Tran et al. 2019). Many investors employ value investment strategies to improve the performance of their investments' portfolios. Long investors value those firms which are underpriced, and short investors value those that are overpriced. It has also been well documented that stock prices follow a random walk behavior suggesting there is no information available on past price movement to predict the trend of movement in future prices (Fama 1965). Nevertheless, certain stock market anomalies refute the efficient market hypothesis. The momentum and contrarian effect is one of the anomalies that has been used to earn profit. Jegadeesh and Titman (1993) were the first who studied the momentum effect, defined as selling losers and buying winners, to earn profits. Chan et al. (1999) identified that when there is an announcement regarding the earnings of a firm, the market tends to underreact to this announcement, suggesting that investors react slowly to this type of new information, resulting in a price momentum. Hong and Stein (1999) presented a behavioral model where momentum was a result of interaction between momentum traders and arbitrage traders. Another concept of momentum effect explains that it is a tendency of an asset that performs well (low) in the past to over (under) perform in the future (Zaremba 2019).

Another well-known anomaly is the "contrarian effect". This anomaly is a long-term phenomenon defined as "the tendency of an asset that has been performing well (poorly) in the past to under (over) perform in the future. In a contrarian strategy, investors can obtain extra returns by short selling the stocks that underperformed the market in the past and buying the stocks that outperformed in the past. Researchers have documented the profitability of a contrarian strategy in various periods and 
markets (Bissoondoyal-Bheenick et al. 2014). De Bondt and Thaler (1985) argued that, with time, past losers become underpriced and past winners overpriced because of the overreaction of the investor to both the bad and good news.

Researchers have established momentum and contrarian strategies for credit risk. Sasaki and Miyazaki (2012) found a positive relationship between the contrarian return and credit risk (using credit rating as a proxy) in the Japanese stock market. Stock markets decline during recessions and as a result value premium also declines (Siegel 1994). When there is a recession, it means there is a significant economic decline for at least six months, as a result, the premium value of shares also reduces so investors are unable to generate an excess return (Siegel 1994). Chordia and Shivakumar (2002) and Avramov et al. (2007) found that when there was economic expansion that an investor could generate extra returns by using the momentum strategy. Sasaki and Miyazaki (2012) found a relationship between the contrarian strategy and the business cycle. They suggested that when there was an economic recession it was not possible to generate excess returns by using the contrarian strategy, whereas when there was an economic expansion it was possible to generate excess return through contrarian strategy.

We face a different level of credit risk in different phases of the business cycle. Sasaki and Miyazaki (2012) found that an excess return could be generated in an economic expansion and no excess return could be generated during an economic recession through the contrarian strategy. However, we aim to find whether there is a relationship between momentum and the contrarian strategy and credit risk in emerging markets. In this paper, we examine the relationship among momentum, contrarian and credit risk using data from emerging markets, including Bangladesh, India, and Pakistan. We analyze the impact of credit risk on momentum strategy (for three to twelve months) and contrarian strategy (for a longer period of 24 to 60 months) by investors. Investors use these investment strategies to generate an excess return in volatile markets (Aravind 2016). We use the expected default probability from the distance to default $(D D)$ by Kealhofer, McQuown, and Vasicek (KMV) model as a proxy for credit risk, and we show that momentum and contrarian exist in low, medium and high credit risky firms.

First, we analyze the momentum and contrarian strategies in these markets. Secondly, we determine whether or not investors can generate an extra return by using momentum and contrarian strategies. Lastly, we also examine how returns from momentum and contrarian strategies are affected by certain categories of credit risk (low, medium, and high).

The remainder of the paper is structured as follows: We provide a brief review of the literature in Section 2, we present data and methodology in Section 3, Section 4 provides the results and discussion, and Section 5 concludes the paper with suggestions for further studies.

\section{Review of Literature}

Jegadeesh and Titman (1993) investigated the momentum profitability in AMES and NYSE and the time period they covered was 1965 to 1989. They used a different formation period and different holding periods from three to twelve months. They considered the strategies with and without a gap of one week between formation and holding periods. They found that all of the 32 zero-cost momentum portfolios showed positive returns and all were statistically significant except one, i.e., $3 \times 3$ where the formation period was three months and the holding period was also three months. They found that the momentum effect existed in the American stock market with an average monthly return of one percent. They reported that risk and underreaction of stock prices were not factors contributing to these average returns of portfolios. Conrad and Kaul (1998) also studied the momentum effect in the American stock market but the time period covered was from 1962 to 1989 and they changed the strategies from three to twelve months to one to thirty-six weeks. They found that except $1 \times 1$ where the formation period was one week and the holding period was also one week, all other zero-cost portfolios showed statistically significant positive returns. They made a similar conclusion to that of Jegadeesh and Titman (1993) that the momentum effect exists in the American stock market. 
Pyo and Shin (2013) worked on the gainfulness of momentum exchanging in the Korean securities exchange. In particular, their point was to examine of the relationship between momentum returns and quirky instability (IVol) to determine if momentum benefits could be clarified by IVol. Portfolios were shaped in light of their past execution and they analyzed the momentum, or contrarian returns, as the distinction in the middle of winning and losing portfolios. To affirm that the momentum methodology gave abundance returns, they concentrated on the relationship between momentum returns and IVol. Fama (1965) three-factor model was additionally inspected to see whether efficient risk influenced the momentum benefits. Firm size, stock cost, and turnover were controlled to decide heartiness. At long last, a time-series relationship between total IVol and momentum return was positive. Hong and Stein (1999) worked on a concept of dubbed news watchers and momentum traders that was contrary to asset pricing (where investors are rational and have infinite estimation capacity). The authors reported that when there was news in the market, investors underreact to that news because prices are only partially adjusted to the news. They explained that the underreaction of news watchers was exploited by the momentum traders. The strategies used by momentum traders was to first shift the prices back to their fundamental values. As a result, investors overreacted to the information at the end and when prices reached their fundamental values, the reversal occurred.

Drew et al. (2007) worked on the momentum strategies and predictive power of trading volume in the Australian stock market. Portfolios were created according to Lee and Swaminathan (2000) approach, and ranking was based on past returns and past volume. They found that, in the Australian market, strong momentum existed between 1988 and 2002. They reported that to provide information about the stocks, momentum was an important factor. The magnitude and consistency of momentum was predictable through trading volume. Shah and Shah (2015) studied the momentum effect in the Pakistani stock market, i.e., Karachi Stock Exchange. They studied momentum profits by using monthly return data. They used Jegadeesh and Titman (1993) methodologies for ranking, as well as for portfolio construction. They ranked the stocks based on their past returns of formation period into winner and loser portfolios, and then held these portfolios for different holding periods ranging from three to twelve months. They found that by holding the momentum portfolio, investors could generate abnormal returns. The same results were obtained when small stocks were excluded and also when a different sample period was used. Chordia and Shivakumar (2002) studied the relationship between momentum profits and economic variables. They showed that, in their sensitivity, momentum returns varied systematically to the common macroeconomic variables. They found that there was little impact from stock-specific information, i.e., historical returns, on the momentum profits when cross-sectional differences in expected returns (with a lag of one month ahead of the macroeconomic variable) were taken into account. Their analysis of empirical evidence showed that, in the expansionary period, momentum profits were high, whereas they were negative during the recession period, although the negative relationship during the recession period was not statistically significant.

Rahman and Mohsin (2012) conducted a study to examine the momentum profitability in the Karachi stock exchange. They used sixteen momentum strategies by following equal-weighted, full rebalancing, and decile techniques. They used the data of 300 listed firms for the time period from 1999 to 2007 and found that, out of sixteen strategies, only one strategy had a positive return of zero-cost momentum portfolios and the strategy showed the decreeing trend in losses. As a result, they extended their analysis to a long period. They found some evidence of the momentum effect. These momentum effects remained significant even when the sample was changed. Ansari and Khan (2012) conducted a study to examine the existence of momentum anomaly in the Indian stock market. They used different risk base, as well as behavioral models, to identify the sources of momentum profitability. For behavioral models, they used $\mathrm{R}^{2}$, idiosyncratic volatility, and delay measures. They also followed the Jegadeesh and Titman (1993) methodology for portfolio construction, and on the one hand, they found that from 1995 to 2006 there were momentum profits in the Indian stock market, whereas, on the other hand, they used the CAPM and Fama's (1965) models for risk-based models and their results did 
not support the phenomena. There was a positive relationship between momentum and idiosyncratic risk which proved the concept that behavioral factors are the source of momentum profits.

De Bondt and Thaler (1985) found that past losers outperformed past winners, and therefore there was a price reversal for stocks that experienced long-term gains or losses. Their findings were consistent with the overreaction hypothesis. In addition, they also found that their results were inconsistent with two alternative hypotheses that were based on firm size and difference in risk (measured by CAPM-betas). They also examined the seasonal pattern of returns in which they found that excess return in January was related to both short- and long-term past performance and previous period year market return. Conrad et al. (1991) used the simple model in order to clarify the characteristics of short-term returns and determine the importance of several elements. They found that bid-ask error (negative autocorrelation), expected returns (positive autocorrelation), and white noise were related to the security returns. The result showed that bid-ask error and time-varying expected returns that excluded unobservable bid-ask errors and expected return of stock returns, explained up to $24 \%$ of the variance of security returns.

Brozynski et al. (2003) used a questionnaire to survey fund managers to provide evidence that the respondents relied on momentum, contrarian, and buy-and-hold strategies and found that the majority of the respondents relied on these strategies to some degree. Some of the respondents also relied on a single trading strategy and younger, less experienced professionals preferred all kinds of strategies. Subrahmanyam (2005) proposed a model that was based on both behavior effects and risk-averse inventory phenomena to investigate the short-term reversals. His results were consistent with Jegadeesh (1990) who examined the monthly return reversal effect. This reversal played an important role in monthly reversal according to the financial markets' agent. Subadar and Hossenbaccus (2010) tested the presence of contrarian profits on the Mauritius stock exchange using the data of all 40 listed firms on the official market from 2001 to 2009. Their study showed the evidence of contrarian return. They noted negative excess returns for all portfolios by considering the market return. Their result showed strong support for the portfolio management strategy and weak support for the overreaction hypothesis. Furthermore, they also tested the size, price, earning per share, and book-to-market value. The results showed that average market returns are higher than size and price-based portfolios.

Paškevičius and Mickevičiūte (2011) tested the presence of contrarian profits on NASDAQ and OMX Vilnius stocks from 2003 to 2010. They used the holding period returns to evaluate the contrarian strategy. They showed that there were no holding period returns during the decline period of the NASDAQ OMX Vilnius. They suggested contrarian strategy was a better option during the growth period because stocks were overrated during the growth period as compared with the standard market index. Chen et al. (2012) tested the short-term under market state contrarian strategy by using the weekly dataset of shares from 1995 to 2010 that were listed on Chinese stock exchange. They found that contrarian profits were significant, especially after 2007 when China, along with the world, faced a financial crisis. They found that profits were insignificant in the intermediate time horizon that was generated from the momentum and contrarian strategies. Furthermore, they found that contrarian profits with a one to two months holding period were significant after adjusting for microstructure effects. Moreover, they concluded that contrarian profits were higher during the down market as compared with the profits during the upmarket. In other words, they suggested that a contrarian strategy was a shelter when the market declined. Hameed and Mian (2015) tried to reinvestigate the short-term reversal phenomenon and used stocks grouped by industries that were exposed to changes in supply and demand. They confirmed that return reversals were not affected by standard risk adjustment. They also suggested that inter-industry reversal was not influenced by the January effect.

Avramov et al. (2007) studied the relationship of momentum profits with credit risk. They described that firms with a low grade credit risk had statistically significant and economically large momentum profits. However, this effect did not exist among the firms that had a high grade for credit risk. Their sample consisted of 3578 firms that were listed on the NYSE, AMEX, and NASDAQ from July 1985 to December 2003. They showed that the high momentum returns in high credit risk stocks were due to 
the deteriorating performance of loser stocks and improving performance of winner stocks over the formation and holding period, as well as losers stock became less liquid and volatility increased and winner stocks became more liquid and their volatility decreased. This further signifies that momentum returns are different as per levels of credit rating. High risk ensures momentum profits, mean that momentum investing strategies are profitable only for the firms having high or medium credit risk. In addition, this relationship implies that aggregate momentum profits are high during a recession when credit risk is a major matter of concern for firms. Avramov and Zhou (2010) investigated the relationship among financial distress, pattern in cross-sectional average stock return, and momentum profits. They used credit ratings as a proxy for credit risks and found that momentum profits were significant and economically high which meant that momentum returns were highly dependent on the level of credit risk. They further showed that the price momentum profits among other anomalies depended on financial distress periods. They used downgrading of credit rating as a proxy for financial distress. In the absence of financial distress periods, there were insignificant and small momentum profits from the sample. There was no momentum profit during the period of upgrade credit ratings. These explanations show that additional risks are compensated by momentum profits. Lu et al. (2014) studied the relationship between momentum profits and credit risk in the Taiwan Stock market. They classified the credit risk into three groups, i.e., low, medium, and high. They used the distance to default point of the KMV model as a proxy for credit risk. They found that the momentum effect existed in the Taiwan stock market. Their results were consistent with the results of Avramov et al. (2007) that the high credit risk group had high momentum profits as compared with the low and medium credit risk firms. Their findings confirmed the investment theory of high risk, high returns.

Sasaki and Miyazaki (2012) found a relationship between the contrarian return and credit risk (used credit rating as proxy) in the Japanese stock market. They verified the contrarian return differed by credit rating at a statistically significant level by applying Wilcoxon's signed-rank test. In their research, they investigated contrarian return to determine if it was indispensable to adopt credit rating or not. In other words, they tried to explain whether the factors explaining credit rating could explain contrarian return. They clarified the relationship between contrarian return and credit rating by dividing the contrarian return into its components, and then examined the relationship between them. Bissoondoyal-Bheenick et al. (2014) found a relationship between credit risk and return. They compared the returns of high and low credit risk firms by considering the credit ratings given by standard and poor. They used a sample of the most developed nations of Asia Pacific from 1990 to 2012. The results showed that a credit risk and return relationship existed in both the Japanese and Australian stock market. They concluded that downgrade announcements of firms in the market explain the credit risk and return anomaly and significantly impact the cross-section of returns. Yu et al. (2019) used weekly returns of winner-minus-loser portfolios, in China, and found that weekly stock return reversals were significant. Umutlu (2015) and Zaremba and Konieczka (2016) showed a positive relationship between price risk and future stock returns. Khan et al. (2017) conducted a study to analyze the relationship between positive or negative market volatility and momentum profits and concluded a negative influence of market volatility on momentum profits. Hoque et al. (2020) concluded that the momentum strategy generated negative returns, whereas investors expected high returns from the growth-oriented stock of oil and gas stocks in Malaysia. On the basis of the above literature, we develop the following hypotheses for our study:

Hypothesis 1 (H1). Momentum and contrarian strategies' returns are significantly related to low credit risk;

Hypothesis 2 (H2). Momentum and contrarian strategies' returns are significantly related to medium credit risk;

Hypothesis 3 (H3). Momentum and contrarian strategies' returns are significantly related to high credit risk. 


\section{Methodology}

We obtained price data from 2008 to 2014 for stocks listed on the Pakistan, Bombay, and Dhaka stock exchange from their official websites. Data to compute the distance to default $(D D)$ of the KMV model was taken from the financial statements of the listed firms available in their annual reports. The annual T-bill rate of Pakistan, India, and Bangladesh was used as the risk-free rate. Stocks whose data were missing during the formation and holding periods were excluded from the analysis.

The methodology for constructing the momentum portfolio followed that of Jegadeesh and Titman (1993). For the momentum strategies, stocks were selected and ranked based on the return of their past J month (where J is 3, 6, 9, 12) and hold for K-month (where $\mathrm{K}$ is 3, 6, 9, 12). All stocks were ranked on the basis of their cumulative return over the 6 months formation period, and then two portfolios were created that were designated as a winner and a loser. The winner portfolio contained stocks that had performed well during the past 6 month formation period, whereas the loser portfolio contained stocks that had performed poorly over the 6 months formation period. Portfolios were equally weighted at the formation period and held for $\mathrm{K}$ months holding period. The zero-cost momentum strategy means winner minus loser. If the return of the zero-cost momentum strategy was greater than the market index, this suggested that the market was inefficient as investors could generate extra returns by using the momentum strategy.

We followed the methodology of De Bondt and Thaler (1985) to construct the contrarian portfolios. Stocks were selected based on their cumulative returns, and then winner portfolios and loser portfolios were created. Winner portfolios contained stocks that had performed well over the past 24 month formation period, whereas loser portfolios contained stocks that had performed poorly over the past 24 month formation period. The output of the contrarian strategy is a zero-cost strategy which means loser minus winner (buying losers and selling winners). If the value is greater than zero ( $A L-A w>0)$, investors can generate abnormal returns by using a contrarian strategy.

Risk measures are common tools to evaluate and mitigate the risk of financial position (Garrido and Okhrati 2018). We measured credit risk using the KMV model (Merton 1976). According to this model, credit risk is divided into three categories, i.e., low, medium and high. According to the assumptions of Merton (1976) model, the equity value of the firm should be equal to the following equation:

$$
V s=V a N(d 1)-F e^{-r t} N(d 2)
$$

where, $V s$ is the firm's equity's market value, $V a$ is the firm's asset's market value, $F$ is the face value of debt, $r$ is the risk-free rate of return, and $N($.$) is the cumulative standard normal distribution.$

$$
\begin{gathered}
d 1=\frac{\ln \left(\frac{V a}{F}\right)+\left(r+\frac{1}{2} \sigma_{A}^{2}\right) t}{\sqrt{\sigma_{A}^{2} t}} \\
d 2=d 1-\sqrt{\sigma_{A}^{2} t}
\end{gathered}
$$

where $t$ is the time horizon of the debt's face value and $\sigma_{a}$ is the underlying asset's volatility

The following equation is used to find the relation between firms' volatility and equity of the firm:

$$
\sigma_{E}=\left(\frac{V a}{V s}\right) N(d 1) \sigma_{A}
$$

In order to convert the value and the volatility of equity of firms into an implied default point in the KMV model, the nonlinear Equations (1) and (2) are used. To implement the KMV model, we followed three steps. First, using the data of historical returns of stocks, the volatility of equity is estimated. Second, choose a time horizon, and then there is a measurement of the face value of debt of the firm. The last step solves Equations (1) and (2) to find the values of $V a$ and $\sigma_{A}$.

The distance to default $(D D)$ is our measure of credit risk (Fong et al. 2005) which is computed as follows: 


$$
D D=\frac{E\left(V_{A}\right)-D P T}{\sigma_{A}}
$$

where $D P T$ is the default point. Next, we categorize the portfolios into three credit-risk classes (low, medium, and high). In order to examine the momentum and contrarian returns for the various types of credit risk (low, medium, and high), stocks are classified first based on credit risk, and then on the returns of the past six month period.

\section{Empirical}

In this section, we present an analysis of our study. We explain returns from momentum and contrarian strategies for different holding periods. Furthermore, these strategies are investigated with different levels of risk.

The momentum strategies are implemented for the period from 2008 to 2014 . The results of monthly average returns are presented in Table 1. The winner and losers are the top and bottom 10 stocks, respectively, on the basis of past returns. It is evident that momentum profitability exists for short-, long- and medium-term holding periods. Results further imply that investors can earn excess stock returns by applying investment strategies that relate to selling losers while buying winner stocks. These results suggest that the stock markets of Pakistan, India, and Bangladesh are inefficient. These findings are consistent with many similar studies in the literature (Agathee 2012; Liang 2012; Rahman and Mohsin 2012; Shah and Shah 2015).

Table 1. Returns from momentum strategy for the different holding periods.

\begin{tabular}{|c|c|c|c|c|}
\hline & & Pakistan & India & Bangladesh \\
\hline Years & Holding Period & \multicolumn{3}{|c|}{ Winner Minus Loser } \\
\hline \multirow[t]{4}{*}{2008} & $K=3$ & 0.0188 & -0.01854 & -0.0668 \\
\hline & $K=6$ & 0.2312 & 0.038002 & -0.0886 \\
\hline & $K=9$ & 0.2189 & 0.136179 & -0.12337 \\
\hline & $K=12$ & 0.1897 & -0.5908 & -0.28923 \\
\hline \multirow[t]{4}{*}{2009} & $K=3$ & 0.0222 & 0.062376 & 0.268794 \\
\hline & $K=6$ & 0.000381 & 0.031907 & 0.231891 \\
\hline & $K=9$ & 0.0018 & -0.08668 & 0.319653 \\
\hline & $K=12$ & 0.0326 & -0.15083 & -0.18341 \\
\hline \multirow[t]{4}{*}{2010} & $K=3$ & 0.0422 & 0.062638 & 0.048833 \\
\hline & $K=6$ & 0.1688 & 0.107122 & 0.105621 \\
\hline & $K=9$ & 0.2625 & 0.166243 & 0.22115 \\
\hline & $K=12$ & 0.4980 & -0.09751 & 0.283725 \\
\hline \multirow[t]{4}{*}{2011} & $K=3$ & 0.03851 & 0.098095 & 0.021584 \\
\hline & $K=6$ & 0.012413 & 0.237992 & 0.097435 \\
\hline & $K=9$ & 0.432597 & 0.058875 & 0.233055 \\
\hline & $K=12$ & 0.6262 & 0.232839 & 0.093401 \\
\hline \multirow[t]{4}{*}{2012} & $K=3$ & 0.1561 & 0.035358 & 0.059826 \\
\hline & $K=6$ & 0.3735 & 0.148605 & 0.045589 \\
\hline & $K=9$ & 0.4063 & 0.083661 & 0.141754 \\
\hline & $K=12$ & 0.3625 & -0.09352 & 0.25216 \\
\hline \multirow[t]{4}{*}{2013} & $K=3$ & 0.0442 & 0.179575 & 0.219989 \\
\hline & $K=6$ & 0.1315 & -0.0274 & 0.054988 \\
\hline & $K=9$ & 0.5143 & 0.015913 & 0.197796 \\
\hline & $K=12$ & 0.7181 & -0.2376 & 0.236246 \\
\hline \multirow[t]{4}{*}{2014} & $K=3$ & 0.0982 & 0.011189 & 0.087118 \\
\hline & $K=6$ & 0.0421 & 0.015577 & 0.032048 \\
\hline & $K=9$ & - & - & - \\
\hline & $K=12$ & - & - & - \\
\hline
\end{tabular}


Table 2 presents the results of the contrarian strategy. The evidence of profitability exists in 24 , 36,48 , and 60 months holding periods. It is also clear from the table that, in all years, the returns from contrarian strategy are greater than zero with contrarian profits present overall holding periods. Thus, the contrarian strategy can be used to generate excess returns. Results justify that investors can generate excessive stock returns by adopting investment strategies that relate to selling winners and buying loser portfolios. Again, these findings are consistent with that of many other studies in the literature (Hameed and Mian 2015; Balvers et al. 2000).

Table 2. Returns from contrarian strategy for different holding periods.

\begin{tabular}{|c|c|c|c|c|}
\hline & & Pakistan & India & Bangladesh \\
\hline Years & Holding Period & \multicolumn{3}{|c|}{ Loser Minus Winner } \\
\hline \multirow[t]{4}{*}{2008} & $K=24$ & 0.0496 & -0.176 & 0.0439 \\
\hline & $K=36$ & 0.8579 & 0.1039 & 0.0879 \\
\hline & $\mathrm{K}=48$ & 0.7721 & 0.0701 & 0.0272 \\
\hline & $K=60$ & 0.0189 & 0.028 & 0.079 \\
\hline \multirow[t]{4}{*}{2009} & $K=24$ & 0.1454 & -0.007 & 0.0831 \\
\hline & $K=36$ & 0.0563 & 0.0743 & 0.0843 \\
\hline & $\mathrm{K}=48$ & 0.3622 & 0.0277 & 0.0374 \\
\hline & $K=60$ & 0.0211 & 0.038 & 1.1087 \\
\hline \multirow[t]{3}{*}{2010} & $K=24$ & 0.0326 & 0.0668 & 0.0265 \\
\hline & $K=36$ & 0.4046 & 0.0233 & 0.0597 \\
\hline & $\mathrm{K}=48$ & 0.0192 & 0.3747 & 0.1265 \\
\hline \multirow[t]{2}{*}{2011} & $K=24$ & 0.5064 & 0.0138 & 0.0188 \\
\hline & $\mathrm{K}=36$ & 0.9125 & 0.2299 & 0.0444 \\
\hline 2012 & $\mathrm{~K}=24$ & 0.0042 & 0.3856 & 0.0307 \\
\hline
\end{tabular}

Table 3 presents the momentum profits of the three credit risk groups. We find that momentum strategy returns depend on credit risk. For all the years, when a high credit risk portfolio is held for three, six, nine, and twelve months (W-L) returns are greater than zero, with some exceptions. In the case of Pakistan, when high credit risk portfolios are held for three months, the momentum returns are negative. In all other holding periods and all years, the returns are greater than zero. For the other two countries, the returns are greater than zero which shows that the excess returns can be produced by investments with high credit risk. Similar results are obtained when the portfolio contains medium credit risk firms. Conversely, no excess returns can be obtained when this strategy is applied to low-credit-risk investment portfolios suggesting that such portfolios are informationally efficient. Similar findings have been reported by others (Avramov et al. 2007).

Table 4 presents the contrarian profits of three credit risk groups and similarly shows that contrarian strategy returns are related to credit risk. For all the years, for the Pakistan stock exchange, when high-credit-risk portfolio is held for $24,36,48$, and 60 months the (L-W) returns are greater than zero. Identical results are found for the Bombay and Dhakar stock exchanges. Similar results are obtained when the portfolio contains medium-credit-risk firms. Conversely, no excess returns are obtained when this strategy is applied to low-credit-risk portfolios. These results are consistent with that of others (Avramov et al. 2007; Sasaki and Miyazaki 2012; Bissoondoyal-Bheenick et al. 2014). Generally, outcomes describe that returns during 2008 are comparatively lower or negative in some cases as compared with returns during other periods. This ensures the impact of global financial crises on investment strategies which ultimately affects portfolio returns. We confirm that major spillover effects of global financial crises exist in emerging markets (Mensi et al. 2016). This is obvious because, during crises, the issues relating to managing risk and allocating assets are important (Dimitriou and Kenourgios 2013). In addition, global financial crises generate a synchronized decline in financial markets across the world along with great capital outflow from emerging economies (Dua and Tuteja 2016). 
Table 3. Momentum returns by credit risk.

\begin{tabular}{|c|c|c|c|c|c|c|c|c|c|c|}
\hline & \multirow[b]{2}{*}{ Holding } & \multicolumn{9}{|c|}{ Winner Minus Loser Returns Based on Credit Risk } \\
\hline & & \multicolumn{3}{|c|}{ Pakistan } & \multicolumn{3}{|c|}{ India } & \multicolumn{3}{|c|}{ Bangladesh } \\
\hline & & & & & & Credit Risl & & & & \\
\hline Years & Period & High & Medium & Low & High & Medium & Low & High & Medium & Low \\
\hline \multirow[t]{4}{*}{2008} & $K=3$ & -0.118 & -0.319 & -0.163 & 0.111 & 0.106 & -0.101 & 0.027 & -0.006 & -0.077 \\
\hline & $K=6$ & 0.015 & 0.333 & -0.111 & 0.248 & 0.109 & -0.282 & 0.136 & 0.069 & -0.099 \\
\hline & $K=9$ & 0.322 & 0.396 & -0.223 & 0.263 & 0.239 & -0.114 & 0.293 & 0.044 & -0.125 \\
\hline & $\mathrm{K}=12$ & 0.056 & 0.258 & -0.305 & 0.088 & 0.747 & -0.589 & 0.456 & 0.170 & -0.359 \\
\hline \multirow[t]{4}{*}{2009} & $K=3$ & 0.433 & -0.188 & -0.128 & 0.029 & 0.008 & -0.265 & 0.296 & -0.153 & -0.076 \\
\hline & $K=6$ & 0.394 & -0.267 & -0.043 & -0.018 & 0.122 & 0.478 & 0.774 & 0.155 & -0.569 \\
\hline & $K=9$ & 0.487 & 0.329 & -0.045 & -0.055 & 0.092 & 0.576 & 0.679 & 0.511 & -0.478 \\
\hline & $\mathrm{K}=12$ & 0.179 & 0.009 & -0.241 & -0.183 & 0.024 & -0.035 & 0.238 & 0.579 & -0.852 \\
\hline \multirow[t]{4}{*}{2010} & $K=3$ & -0.122 & -0.193 & -0.077 & 0.185 & 0.044 & -0.114 & 0.396 & -0.147 & -0.034 \\
\hline & $K=6$ & 0.184 & 0.201 & 0.488 & 0.240 & 0.003 & -0.029 & 0.473 & 0.272 & -0.378 \\
\hline & $K=9$ & 0.009 & 0.3013 & -0.203 & 0.334 & 0.021 & -0.178 & 0.201 & 0.744 & -0.591 \\
\hline & $\mathrm{K}=12$ & 0.011 & 0.393 & -0.143 & 0.114 & 0.004 & -0.139 & 0.308 & 0.827 & -0.443 \\
\hline \multirow[t]{4}{*}{2011} & $K=3$ & 0.259 & -0.052 & -0.177 & 0.113 & 0.224 & -0.008 & 0.055 & -0.018 & 0.110 \\
\hline & $K=6$ & 0.099 & 0.149 & -0.144 & 0.379 & 0.411 & -0.008 & 0.789 & 1.221 & -0.921 \\
\hline & $K=9$ & 0.209 & 0.094 & -0.015 & 0.048 & 0.101 & -0.036 & 1.349 & 1.254 & -0.536 \\
\hline & $\mathrm{K}=12$ & 0.355 & 0.089 & -0.202 & 0.308 & 0.301 & -0.04 & 0.171 & 0.933 & -0.337 \\
\hline \multirow[t]{4}{*}{2012} & $K=3$ & -0.044 & -0.284 & -0.028 & 0.202 & 0.024 & -0.172 & 0.146 & -0.137 & -0.095 \\
\hline & $K=6$ & -0.051 & 0.073 & -0.085 & 0.452 & 0.107 & -0.141 & -0.002 & 0.027 & -0.047 \\
\hline & $K=9$ & 0.121 & 0.025 & -0.235 & 0.484 & 0.084 & -0.121 & 0.698 & 0.193 & -0.066 \\
\hline & $\mathrm{K}=12$ & 0.128 & 0.159 & -0.367 & 0.598 & 0.469 & -0.127 & 0.321 & 0.177 & -0.684 \\
\hline \multirow[t]{4}{*}{2013} & $K=3$ & -0.483 & -0.118 & -0.299 & 0.036 & 0.319 & -0.056 & 0.194 & -0.137 & 0.185 \\
\hline & $K=6$ & 0.138 & 0.602 & -0.183 & 0.004 & 0.073 & -0.236 & 0.464 & 0.137 & -0.052 \\
\hline & $\mathrm{K}=9$ & 0.3187 & 0.882 & -0.002 & 0.177 & 0.127 & -0.171 & 0.161 & 0.022 & -0.047 \\
\hline & $\mathrm{K}=12$ & 0.646 & 0.897 & -0.382 & 0.563 & 0.019 & -0.353 & 0.333 & 0.128 & -0.521 \\
\hline \multirow[t]{2}{*}{2014} & $K=3$ & -0.233 & -0.377 & -0.259 & 0.239 & 0.17 & -0.137 & 0.051 & 0.358 & -0.152 \\
\hline & $K=6$ & 0.221 & 0.159 & -0.085 & 0.277 & 0.236 & 0.316 & 0.483 & 0.354 & -0.035 \\
\hline
\end{tabular}

Note: Momentum returns and credit risk (low, medium, and high), stocks are classified first on the basis of credit risk and then returns of the past six month period.

Table 4. Contrarian profitability by credit risk.

\begin{tabular}{|c|c|c|c|c|c|c|c|c|c|c|}
\hline & \multirow[b]{2}{*}{ Holding } & \multicolumn{9}{|c|}{ Loser Minus Winner Returns on the Basis of Credit Risk } \\
\hline & & \multicolumn{3}{|c|}{ Pakistan } & \multicolumn{3}{|c|}{ India } & \multicolumn{3}{|c|}{ Bangladesh } \\
\hline & & & & & & Credit Risk & & & & \\
\hline Years & Period & High & Medium & Low & High & Medium & Low & High & Medium & Low \\
\hline \multirow[t]{4}{*}{2008} & $K=24$ & 0.2201 & 0.056 & 0.2620 & 0.9145 & -0.672 & -0.063 & 0.3000 & 1.132 & -0.225 \\
\hline & $K=36$ & 0.0445 & 0.002 & -0.090 & 0.3893 & 0.069 & -0.230 & 0.3499 & 0.379 & 0.003 \\
\hline & $\mathrm{K}=48$ & 0.1966 & 0.209 & -0.312 & 0.0325 & 0.244 & 0.1922 & 0.0888 & 0.743 & -0.170 \\
\hline & $K=60$ & 0.0173 & 0.047 & -0.023 & 0.3841 & 0.514 & 0.1856 & 0.1579 & 0.035 & -0.214 \\
\hline \multirow[t]{4}{*}{2009} & $\mathrm{~K}=24$ & 0.0178 & 0.108 & -0.058 & 0.0976 & 0.487 & -0.347 & 0.0681 & 0.828 & -0.219 \\
\hline & $K=36$ & 0.0909 & 0.508 & -0.145 & 0.0049 & 0.114 & 0.0742 & 0.0015 & 0.042 & -0.583 \\
\hline & $\mathrm{K}=48$ & 0.8057 & 1.175 & -0.212 & 0.1569 & 0.097 & -0.061 & 0.1477 & 0.202 & 0.162 \\
\hline & $K=60$ & 3.2119 & 0.155 & -0.298 & 0.2940 & 0.311 & -0.048 & 0.2983 & 3.275 & 0.122 \\
\hline \multirow[t]{3}{*}{2010} & $K=24$ & 0.0153 & 0.116 & -0.093 & 0.1793 & 0.108 & -0.082 & -0.344 & -0.158 & 0.063 \\
\hline & $K=36$ & 0.5586 & 0.050 & -0.072 & 0.0094 & 0.109 & -0.385 & 0.2865 & 0.084 & -0.059 \\
\hline & $\mathrm{K}=48$ & 0.7970 & 1.480 & 0.0081 & 0.1171 & 0.383 & -0.099 & 0.0523 & 0.097 & -0.005 \\
\hline \multirow[t]{2}{*}{2011} & $K=24$ & 0.6173 & 0.218 & -0.201 & 0.0101 & 0.044 & -0.152 & 0.3141 & 0.023 & -0.094 \\
\hline & $K=36$ & 0.3159 & 0.230 & -0.268 & 0.0799 & 0.123 & 0.1301 & 0.3249 & 0.003 & 0.294 \\
\hline 2012 & $K=24$ & 0.2156 & 0.210 & 0.3331 & 0.2926 & 0.189 & 0.0264 & 0.1641 & 0.136 & 0.052 \\
\hline
\end{tabular}

Note: In order to find different contrarian returns for types of credit risk (low, medium, and high), we classify the stocks first on the basis of credit risk, and then on the returns of past 24 month periods. 
Table 5 shows the significance level of the relationship of our excess return (that we generate by applying a momentum strategy in Table 3 ) and the credit risk. It is evident from Table 5 that the momentum returns for portfolios having high-credit-risk firms and six, nine, and twelve month holding period are significant, which shows that when a firm bears high credit risk, then by applying the momentum strategy of these stocks, the firm's investor can generate an excess return on medium- and long-term investments. Similar results are obtained for medium credit risk in case of a momentum strategy which supports $\mathrm{H} 2$. In the case of low credit risk, an investor cannot generate excess returns by applying momentum strategies because there is an insignificant relationship between momentum strategy returns and a low credit risk. Even negative returns are generated for short-term investment periods. Therefore, we reject H1 that is momentum strategy returns are significantly related to low credit risk firm". The results of our study also support the investment theory that "high-risk high return", i.e., portfolio exposure to high risk has high returns. Similar results were found in many other studies (Avramov et al. 2007).

Table 5. Hypotheses testing W.R.T. momentum returns.

\begin{tabular}{|c|c|c|c|c|c|c|}
\hline Countries & Holding Periods & Types of Risk & Coef. & $t$-Value & $F$-Stat & $\mathbf{R}^{2}$ \\
\hline \multirow{12}{*}{ Pak } & \multirow{3}{*}{$\begin{array}{l}3 \text { months holding } \\
\text { period return }\end{array}$} & High Risk & $2.97 \times 10^{-12}$ & 0.658 & 0.433 & 0.079 \\
\hline & & Medium risk & $-3.94 \times 10^{-13}$ & -0.538 & 0.289 & 0.055 \\
\hline & & Low risk & $1.98 \times 10^{-15}$ & 0.167 & 0.028 & 0.006 \\
\hline & \multirow{3}{*}{$\begin{array}{l}6 \text { months holding } \\
\text { period return }\end{array}$} & High Risk & $5.692 * * *$ & 2.716 & $47.123 * * *$ & 0.718 \\
\hline & & Medium risk & $-3.61 \times 10^{-12 * *}$ & -3.059 & $54.935 * * *$ & 0.818 \\
\hline & & Low risk & $6.26 \times 10^{-15}$ & 0.577 & 0.333 & 0.062 \\
\hline & \multirow{3}{*}{$\begin{array}{l}9 \text { months holding } \\
\text { period return }\end{array}$} & High Risk & $-4.943 * *$ & -2.299 & $57.816^{* * *}$ & 0.832 \\
\hline & & Medium risk & $3.03 \times 10^{-12 * * *}$ & 2.942 & $42.625 * * *$ & 0.830 \\
\hline & & Low risk & $-7.83 \times 10^{-14 *}$ & -2.328 & $5.421 *$ & 0.575 \\
\hline & \multirow{3}{*}{$\begin{array}{l}12 \text { months holding } \\
\text { period return }\end{array}$} & High Risk & $-6.32 \times 10^{-12 * *}$ & -3.176 & $49.141^{* * *}$ & 0.678 \\
\hline & & Medium risk & $5.52 \times 10^{-12 * *}$ & 2.379 & $48.125^{* *}$ & 0.730 \\
\hline & & Low risk & $-4.41 \times 10^{-14}$ & -1.683 & $0.0332 *$ & 0.021 \\
\hline \multirow{12}{*}{ Ind } & \multirow{3}{*}{$\begin{array}{l}3 \text { months holding } \\
\text { period return }\end{array}$} & High Risk & $5.52 \times 10^{-12 * *}$ & 2.379 & $48.125^{* *}$ & 0.730 \\
\hline & & Medium risk & $-2.90 \times 10^{-13 * *}$ & -2.462 & $19.092 * * *$ & 0.754 \\
\hline & & Low risk & $-2.89 \times 10^{-16}$ & -0.505 & 0.255 & 0.049 \\
\hline & \multirow{3}{*}{$\begin{array}{l}6 \text { months holding } \\
\text { period return }\end{array}$} & High Risk & $7.30 \times 10^{-12 * *}$ & 2.212 & $56.033^{* *}$ & 0.801 \\
\hline & & Medium risk & $-3.48 \times 10^{-13 * * *}$ & -2.071 & $10.683^{* * *}$ & 0.702 \\
\hline & & Low risk & $2.41 \times 10^{-15}$ & 1.447 & 2.095 & 0.295 \\
\hline & \multirow{3}{*}{$\begin{array}{l}9 \text { months holding } \\
\text { period return }\end{array}$} & High Risk & $4.04 \times 10^{-12 * *}$ & 2.448 & $21.030 * * *$ & 0.752 \\
\hline & & Medium risk & $2.98 \times 10^{-13 * *}$ & 3.365 & $11.325^{* *}$ & 0.739 \\
\hline & & Low risk & $2.10 \times 10^{-15}$ & 1.1155 & 1.243 & 0.237 \\
\hline & \multirow{3}{*}{$\begin{array}{l}12 \text { months holding } \\
\text { period return }\end{array}$} & High Risk & $-6.51 \times 10^{-13 * *}$ & -3.085 & $34.042^{* * *}$ & 0.661 \\
\hline & & Medium risk & $4.52 \times 10^{-13 * *}$ & 2.249 & $20.082^{* * *}$ & 0.702 \\
\hline & & Low risk & $2.96 \times 10^{-15}$ & 1.073 & 1.1509 & 0.223 \\
\hline \multirow{12}{*}{ Ban } & \multirow{3}{*}{$\begin{array}{l}3 \text { months holding } \\
\text { period return }\end{array}$} & High Risk & $-3.97 \times 10^{-12 * *}$ & 2.612 & $56.994^{* * *}$ & 0.873 \\
\hline & & Medium risk & $-6.21 \times 10^{-12}$ & -0.622 & 0.294 & 0.075 \\
\hline & & Low risk & $2.99 \times 10^{-14}$ & 0.143 & 0.179 & 0.074 \\
\hline & \multirow{3}{*}{$\begin{array}{l}6 \text { months holding } \\
\text { period return }\end{array}$} & High Risk & $6.952 * *$ & 2.569 & $51.987^{* * *}$ & 0.759 \\
\hline & & Medium risk & $4.61 \times 10^{-11 * *}$ & 0.211 & $53.662 * * *$ & 0.786 \\
\hline & & Low risk & $4.16 \times 10^{-11 *}$ & 1.427 & 0.110 & 0.154 \\
\hline & \multirow{3}{*}{$\begin{array}{l}9 \text { months holding } \\
\text { period return }\end{array}$} & High Risk & $9.994 * *$ & 1.998 & $51.664^{* * *}$ & 0.765 \\
\hline & & Medium risk & $-2.03 \times 10^{-11 * * *}$ & -2.183 & $44.964 * * *$ & 0.775 \\
\hline & & Low risk & $-5.36 \times 10^{-14}$ & -1.558 & 0.005 * & 0.412 \\
\hline & \multirow{3}{*}{$\begin{array}{l}12 \text { months holding } \\
\text { period return }\end{array}$} & High Risk & $-5.41 \times 10^{-11 * *}$ & -2.719 & $12.765 * * *$ & 0.775 \\
\hline & & Medium risk & $-7.42 \times 10^{-12} * *$ & -2.108 & $58.411^{* *}$ & 0.815 \\
\hline & & Low risk & $-5.61 \times 10^{-13}$ & -1.417 & 0.109 & 0.129 \\
\hline
\end{tabular}

Note: Pak, Pakistan; Ind, India; Ban, Bangladesh; Coef., coefficients. Regression analysis for different credit risk and momentum returns of the different portfolio (formed by sorting first based on holding period return, and then credit risk),$* * * * * *$ are the significance level at $10 \%, 5 \%$ and $1 \%$ respectively. 
In Table 6, we find that the contrarian returns for portfolios having high-credit-risk firms and 36, 48 , and 60 month holding periods are significant. When a firm bears high credit risk, then, by applying a contrarian strategy on these stocks, an investor can generate excess return on medium- and long-term investments. Therefore, we accept $\mathrm{H} 3$ that is "contrarian strategy returns are significantly related to high credit risk firms". We obtain similar results for medium credit risk in the case of a contrarian strategy which supports H2. In the case of the firms having low credit risk, the investor cannot generate excess return by applying contrarian strategies. Therefore, we reject $\mathrm{H} 1$ that is "contrarian strategy returns are significantly related to low credit risk firm". Our findings signify that when investors apply momentum and contrarian strategies, only those firms are profitable that have high and moderate credit risk. However, results also support the investment "high-risk high return", i.e., portfolio exposures to high risk have high returns and these results are aligned with the findings of previous studies (Avramov et al. 2007; Sasaki and Miyazaki 2012; Bissoondoyal-Bheenick et al. 2014).

Table 6. Hypotheses testing W R T contrarian returns.

\begin{tabular}{|c|c|c|c|c|c|c|}
\hline Countries & Holding Periods & Types of Risk & Coef. & $t$-Value & $F$-Stat & $\mathbf{R}^{2}$ \\
\hline \multirow{12}{*}{ Pak } & \multirow{3}{*}{$\begin{array}{l}24 \text { months holding } \\
\text { period return }\end{array}$} & High Risk & $2.97 \times 10^{-12}$ & 0.658 & 0.433 & 0.079 \\
\hline & & Medium risk & $-3.94 \times 10^{-13}$ & -0.538 & 0.289 & 0.055 \\
\hline & & Low risk & $1.99 \times 10^{-15}$ & 0.167 & 0.028 & 0.006 \\
\hline & \multirow{3}{*}{$\begin{array}{l}36 \text { months holding } \\
\text { period return }\end{array}$} & High Risk & $5.692 * * *$ & 2.716 & $47.123^{* * *}$ & 0.718 \\
\hline & & Medium risk & $-3.61 \times 10^{-12 * *}$ & -3.059 & $54.935 * *$ & 0.818 \\
\hline & & Low risk & $6.26 \times 10^{-15}$ & 0.577 & 0.331 & 0.062 \\
\hline & \multirow{3}{*}{$\begin{array}{l}48 \text { months holding } \\
\text { period return }\end{array}$} & High Risk & $-4.943 * *$ & -2.299 & $57.816^{* * *}$ & 0.832 \\
\hline & & Medium risk & $3.03 \times 10^{-12 * * *}$ & 2.942 & $42.625 * *$ & 0.830 \\
\hline & & Low risk & $-7.83 \times 10-^{14 *}$ & -2.328 & $5.421 *$ & 0.575 \\
\hline & \multirow{3}{*}{$\begin{array}{l}60 \text { months holding } \\
\text { period return }\end{array}$} & High Risk & $-6.32 \times 10^{-12 * *}$ & -3.176 & $49.141^{* * *}$ & 0.678 \\
\hline & & Medium risk & $5.52 \times 10^{-12 * *}$ & 2.379 & $48.125 * *$ & 0.730 \\
\hline & & Low risk & $-4.41 \times 10^{-14}$ & -1.683 & 0.033 * & 0.021 \\
\hline \multirow{12}{*}{ Ind } & \multirow{3}{*}{$\begin{array}{l}24 \text { months holding } \\
\text { period return }\end{array}$} & High Risk & $5.52 \times 10^{-12 * *}$ & 2.379 & $48.125^{* *}$ & 0.730 \\
\hline & & Medium risk & $-2.90 \times 10^{-13 * *}$ & -2.462 & $19.092^{* * *}$ & 0.754 \\
\hline & & Low risk & $-2.89 \times 10^{-16}$ & -0.505 & 0.255 & 0.049 \\
\hline & \multirow{3}{*}{$\begin{array}{l}36 \text { months holding } \\
\text { period return }\end{array}$} & High Risk & $7.30 \times 10^{-12 * *}$ & 2.212 & $56.033^{* *}$ & 0.801 \\
\hline & & Medium risk & $-3.48 \times 10^{-13 * * *}$ & -2.071 & $10.683^{* * *}$ & 0.702 \\
\hline & & Low risk & $2.41 \times 10^{-15}$ & 1.447 & 2.095 & 0.295 \\
\hline & \multirow{3}{*}{$\begin{array}{l}48 \text { months holding } \\
\text { period return }\end{array}$} & High Risk & $4.04 \times 10^{-12 * *}$ & 2.448 & $21.030^{* * *}$ & 0.752 \\
\hline & & Medium risk & $2.98 \times 10^{-13 * *}$ & 3.365 & $11.325^{* *}$ & 0.739 \\
\hline & & Low risk & $2.10 \times 10^{-15}$ & 1.115 & 1.243 & 0.237 \\
\hline & \multirow{3}{*}{$\begin{array}{l}60 \text { months holding } \\
\text { period return }\end{array}$} & High Risk & $-6.51 \times 10^{-13 * *}$ & -3.085 & $34.042 * * *$ & 0.661 \\
\hline & & Medium risk & $4.52 \times 10^{-13 * *}$ & 2.249 & $20.082^{* * *}$ & 0.702 \\
\hline & & Low risk & $2.96 \times 10^{-15}$ & 1.073 & 1.151 & 0.223 \\
\hline \multirow{12}{*}{ Ban } & \multirow{3}{*}{$\begin{array}{l}24 \text { months holding } \\
\text { period return }\end{array}$} & High Risk & $-3.97 \times 10^{-12 * *}$ & 2.612 & $56.994 * * *$ & 0.873 \\
\hline & & Medium risk & $-6.21 \times 10^{-12}$ & -0.622 & 0.294 & 0.074 \\
\hline & & Low risk & $2.99 \times 10^{-14}$ & 0.143 & 0.179 & 0.074 \\
\hline & \multirow{3}{*}{$\begin{array}{l}36 \text { months holding } \\
\text { period return }\end{array}$} & High Risk & $6.952 * *$ & 2.569 & $51.987^{* * *}$ & 0.759 \\
\hline & & Medium risk & $4.61 \times 10^{-11 * *}$ & 0.211 & $53.662 * * *$ & 0.786 \\
\hline & & Low risk & $4.16 \times 10^{-11 *}$ & 1.427 & 0.110 & 0.154 \\
\hline & \multirow{3}{*}{$\begin{array}{l}48 \text { months holding } \\
\text { period return }\end{array}$} & High Risk & $9.994^{* *}$ & 1.998 & $51.664^{* * *}$ & 0.765 \\
\hline & & Medium risk & $-2.03 \times 10^{-11 * * *}$ & -2.183 & $44.964^{* * *}$ & 0.775 \\
\hline & & Low risk & $-5.36 \times 10^{-14}$ & -1.558 & $0.005 *$ & 0.412 \\
\hline & \multirow{3}{*}{$\begin{array}{l}60 \text { months holding } \\
\text { period return }\end{array}$} & High Risk & $-5.41 \times 10^{-11 * *}$ & -2.719 & $12.765^{* * *}$ & 0.775 \\
\hline & & Medium risk & $-7.42 \times 10^{-12 * *}$ & -2.108 & $58.411^{* *}$ & 0.815 \\
\hline & & Low risk & $-5.61 \times 10^{-13}$ & -1.417 & 0.109 & 0.129 \\
\hline
\end{tabular}

Note: Pak, Pakistan; Ind, India; Ban, Bangladesh; Coef., coefficients. Regression analysis for different credit risk and contrarian returns of the different portfolio (formed by sorting first on the basis of holding period return, and then based on credit risk), ${ }^{* * *}, * *$ are the significance level at $10 \%, 5 \%$ and $1 \%$ respectively. 


\section{Conclusions}

Returns from momentum and contrarian strategies remain one of the most persistent anomalies for the stock market. We examine the influence of credit risk (low, medium, and high) on momentum and contrarian returns in the stock markets of Pakistan, India, and Bangladesh. We find that momentum and contrarian profits exist in the stock markets in all three countries. This implies that when a firm bears high credit risk, then by applying momentum and contrarian strategies on these stocks, the investor can generate excess return of their investment. The results follow the investment theory that if a portfolio expects to generate high return, there is a need to bear higher risk. We further find that in the case of medium credit risk, investors can generate excessive returns by applying momentum and contrarian strategies. There are no relationships among low credit risk and momentum and contrarian returns. We also find that momentum strategy is more beneficial for six, nine, and twelve months holding periods and contrarian strategy is prominent for 36, 48, and 60 months holding periods. Our findings suggest that when the holding period is extended, investors get more benefits from the contrarian strategy. The results suggest that when making the investment through momentum and contrarian strategies, investors should also consider the credit risk of the stock. Furthermore, investors should focus more on high and medium credit risk when making investment strategies because high and medium credit risk of firms provide investors opportunities to generate excessive returns. Our study only includes three South Asian economies. However, the study could be extended by incorporating developed economies for different time periods. Therefore, a comparative analysis could be an interesting study.

Author Contributions: A.I.H. worked on conceptualization, writing-review and editing, supervision, T.T. handles the methodology, software and formal Analysis, R.M. contributed in resources, data curation and formal analysis, S.M. worked on conceptualization, writing-original draft preparation, whereas, Z.M. run the methodology and formal analysis. All authors have read and agreed to the published version of the manuscript.

Funding: This research received no external funding.

Conflicts of Interest: We declare there is no conflict of interest.

\section{References}

Agathee, Ushad Subadar. 2012. Momentum strategies on the stock exchange of Mauritius. African Journal of Economic and Management Studies 3: 227-39. [CrossRef]

Ansari, Valeed Ahmad, and Soha Khan. 2012. Momentum anomaly: Evidence from India. Managerial Finance 38: 206-23. [CrossRef]

Aravind, M. 2016. Contrarian and momentum strategies: An investigation with reference to sectoral Portfolios in NSE. The Quarterly Journal of Economics 29: 102-17.

Avramov, Doron, and Guofu Zhou. 2010. Bayesian portfolio analysis. Annual Review of Financial Economics 2: 25-47. [CrossRef]

Avramov, Doron, Tarun Chordia, Gergana Jostova, and Alexander Philipov. 2007. Momentum and credit rating. The Journal of Finance 62: 2503-20. [CrossRef]

Balvers, Ronald, Yangru Wu, and Erik Gilliland. 2000. Mean reversion across national stock markets and parametric contrarian investment strategies. The Journal of Finance 55: 745-72. [CrossRef]

Bissoondoyal-Bheenick, Emawtee, Robert Brooks, and Sirimon Treepongkaruna. 2014. Rating spillover effects on the stock markets. Journal of Multinational Financial Management 25: 51-63. [CrossRef]

Brozynski, Torsten, Lukas Menkhoff, and Ulrich Schmidt. 2003. The Use of Momentum, Contrarian and Buy-\&-Hold Strategies: Survey Evidence from Fund Managers. (No. dp-290). Available online: https: //econpapers.repec.org/paper/handpaper/dp-290.htm (accessed on 12 April 2020).

Chan, Louis KC, Narasimhan Jegadeesh, and Josef Lakonishok. 1999. The profitability of momentum strategies. Financial Analysts Journal 55: 80-90. [CrossRef]

Chen, Qiwei, Ying Jiang, and Yuan Li. 2012. The state of the market and the contrarian strategy: Evidence from China's stock market. Journal of Chinese Economic and Business Studies 10: 89-108. [CrossRef] 
Chordia, Tarun, and Lakshmanan Shivakumar. 2002. Momentum, business cycle, and time-varying expected returns. The Journal of Finance 57: 985-1019. [CrossRef]

Conrad, Jennifer, and Gautam Kaul. 1998. An anatomy of trading strategies. The Review of Financial Studies 11: 489-519. [CrossRef]

Conrad, Jennifer, Gautam Kaul, and Mahendrarajah Nimalendran. 1991. Components of short-horizon individual security returns. Journal of Financial Economics 29: 365-84. [CrossRef]

De Bondt, Werner FM, and Richard Thaler. 1985. Does the stock market overreact? The Journal of Finance 40: 793-805. [CrossRef]

Dimitriou, Dimitrios, and Dimitris Kenourgios. 2013. Financial crises and dynamic linkages among international currencies. Journal of International Financial Markets, Institutions and Money 26: 319-32. [CrossRef]

Drew, Michael E, Madhu Veeraraghavan, and Min Ye. 2007. Do momentum strategies work? Australian evidence. Managerial Finance 33: 772-87. [CrossRef]

Dua, Pami, and Divya Tuteja. 2016. Financial crises and dynamic linkages across international stock and currency markets. Economic Modelling 59: 249-61. [CrossRef]

Fama, Eugene F. 1965. The behavior of stock-market prices. The Journal of Business 38: 34-105. [CrossRef]

Fong, Wai Mun, Wing Keung Wong, and Hooi Hooi Lean. 2005. International momentum strategies: A stochastic dominance approach. Journal of Financial Markets 8: 89-109. [CrossRef]

Garrido, José, and Ramin Okhrati. 2018. Desirable portfolios in fixed income markets: Application to credit risk premiums. Risks 6: 23. [CrossRef]

Hameed, Allaudeen, and G. Mujtaba Mian. 2015. Industries and stock return reversals. Journal of Financial and Quantitative Analysis 50: 89-117. [CrossRef]

Hong, Harrison, and Jeremy C. Stein. 1999. A unified theory of underreaction, momentum trading, and overreaction in asset markets. The Journal of Finance 54: 2143-84. [CrossRef]

Hoque, Mohmmad Enamul, Low Soo Wah, and Mohd Azlan Shah Zaidi. 2020. Do Oil and Gas Risk Factors Matter in the Malaysian Oil and Gas Industry? A Fama-MacBeth Two Stage Panel Regression Approach. Energies 13: 1154. [CrossRef]

Jegadeesh, Narasimhan. 1990. Evidence of predictable behavior of security returns. The Journal of Finance 45: 881-98. [CrossRef]

Jegadeesh, Narasimhan, and Sheridan Titman. 1993. Returns to buying winners and selling losers: Implications for stock market efficiency. The Journal of Finance 48: 65-91. [CrossRef]

Khan, Anila Rafique, Muhammad Waqas, and Arshad Hassan. 2017. Market Volatility and Momentum: Evidence from Pakistani Stock Exchange. Sukkur IBA Journal of Management and Business 4: 82-102. [CrossRef]

Lee, Charles MC, and Bhaskaran Swaminathan. 2000. Price momentum and trading volume. The Journal of Finance 55: 2017-69. [CrossRef]

Liang, Tian. 2012. Momentum and asymmetric information. China Finance Review International 2: $208-30$. [CrossRef]

Lu, Su-Lien, Kuo-Jung Lee, and Chia-Chang Yu. 2014. Momentum strategy and credit risk. Applied Financial Economics 24: 753-62. [CrossRef]

Mensi, Walid, Shawkat Hammoudeh, Duc Khuong Nguyen, and Sang Hoon Kang. 2016. Global financial crisis and spillover effects among the US and BRICS stock markets. International Review of Economics \& Finance 42: 257-76.

Merton, Robert Cox. 1976. Option pricing when underlying stock returns are discontinuous. Journal of Financial Economics 3: 125-44. [CrossRef]

Paškevičius, Arvydas, and Rūta Mickevičiūtè. 2011. Applicability of contrarian investment strategies in small capitalization markets: Evidence from NASDAQ OMX Vilnius. Ekonomika 90: 101-14. [CrossRef]

Pyo, Unyong Howard, and Yong Jae Shin. 2013. Momentum profits and idiosyncratic volatility: The Korean evidence. Review of Accounting and Finance 12: 180-200. [CrossRef]

Rahman, Habib-Ur, and Hasan M. Mohsin. 2012. Momentum effect: Empirical evidence from Karachi stock exchange. The Pakistan Development Review 51: 449-61. [CrossRef]

Sasaki, Daisuke, and Koichi Miyazaki. 2012. Credit Rating Matters in Contrarian Return: Evidence from the Japanese Equity Market. Journal of the Operations Research Society of Japan 55: 107-24. [CrossRef]

Shah, Syed Hamid Ali, and Attaullah Shah. 2015. Can Momentum Portfolios Earn More in the Karachi Stock Exchange? Pakistan Business Review 17: 80-98. 
Siegel, Jeremy J. 1994. Stocks for the Long Run, 1st ed.New York: McGraw-Hill.

Subadar, Ushad Agathee, and Muhammad Anas Hossenbaccus. 2010. Profitability of Contrarian Strategies: Evidence from the Stock Exchange of Mauritius. Organizations \& Markets in Emerging Economies 1: 123-39.

Subrahmanyam, Avanidhar. 2005. Distinguishing Between Rationales for Short-Horizon Predictability of Stock Returns. Financial Review 40: 11-35. [CrossRef]

Tran, Ngoc Phu, Thang Cong Nguyen, Duc Hong Vo, and Michael McAleer. 2019. Market risk analysis of energy in Vietnam. Risks 7: 112. [CrossRef]

Umutlu, Mehmet. 2015. Idiosyncratic volatility and expected returns at the global level. Financial Analysts Journal 71: 58-71. [CrossRef]

Yu, Lin, Hung-Gay Fung, and Wai Kin Leung. 2019. Momentum or contrarian trading strategy: Which one works better in the Chinese stock market. International Review of Economics E Finance 62: 87-105.

Zaremba, Adam. 2019. The Cross Section of Country Equity Returns: A Review of Empirical Literature. Journal of Risk and Financial Management 12: 165. [CrossRef]

Zaremba, Adam, and Przemyslaw Konieczka. 2016. Do quantitative country selection strategies really work? Journal of Investment Strategies 5: 1-33. [CrossRef]

(C) 2020 by the authors. Licensee MDPI, Basel, Switzerland. This article is an open access article distributed under the terms and conditions of the Creative Commons Attribution (CC BY) license (http://creativecommons.org/licenses/by/4.0/). 